\title{
APROXIMACIÓN AL ESTUDIO DE LOS TEXTOS EN ÁRABE DE LOS MORISCO-ANDALUSÍES EN TUNISIA
}

\author{
Abdel-Hakim Gafsi Slama
}

La literatura en lengua española escrita durante las primeras décadas del establecimiento de moriscos españoles, llamados andalusíes en la Regencia de Túnez en el siglo XVII, ha sido objeto, desde hace casi un siglo, de numerosas publicaciones y estudios, algunos de ellos ya clásicos ${ }^{1}$. Pero ningún trabajo de conjunto ha sido realizado hasta ahora sobre la literatura de expresión árabe escrita por esos moriscos y por sus descendientes ${ }^{2}$.

En un mundo cultural del XVII, en el que la transmisión de conocimientos se hacía, las más de las veces, de forma oral y en el que la máxima importancia se daba a la poesía, a la prosa rimada (sadj) o a la prosa de las "sesiones" (maqâma) -géneros literarios que no eran adecuados para el nacimiento y el desarrollo de ideas nuevas- la producción literaria era relativamente escasa.

En esa producción, quedan algunos fragmentos, testimonios o notas relacionados con los andalusíes, en diversas obras literarias y crónicas históri-

1. Ver E. SaAvedra MoraGas, «Índice general de la literatura aljamiada», Memorias de la Real Academia Española, Madrid, VI, 1889, pp. 140-328; J. Ribera y M. Asín PALACios, Manuscritos árabes y aljamiados de la Biblioteca de la Junta, Madrid, 1912; y la bibliografía recogida por L.F. BERNABÉ PONS, Bibliografía de la literatura aljamiado-morisca, Alicante, 1992, a lo que habría que añadir la reciente presentación sintética de él mismo «La asimilación cultural de los musulmanes de España: lengua y literatura de mudéjares y moriscos», Congreso Internacional Chrétiens et Musulmans à l'époque de la Renaissance, Tours, julio 1994 (en prensa).

2. Algunas informaciones y la traducción de algunos textos han sido recogidos por $\mathrm{M}$. DE EPAlza y R. PETIT, Receuil d'études sur les moriscos andalous en Tunisie, Madrid, 1973 [especialmente en los capítulos de A. Turki, H. Pieri, D. Brahimi, M. de Epalza, J. Penella, L.P. Harvey, J. Oliver Asín, M.H. El-Hila y en las notas introductorias de M. de Epalza a esos capítulos]. Reciente síntesis de A.V. RODRIGUEZ, "La literatura aljamiado-morisca del exilio», en M. DE EPALzA (ed.), L'expulsió dels moriscos. Consequiències en el món islàmic $i$ en el món cristià, Barcelona, 1994, pp. 183-194, y buena presentación del contexto socio-literario de los textos hispano-tunecinos, en el estudio de L. LÓPEZ-BARALT, Un Kâma Sûtra español, Madrid, 1992, especialmente pp. 23-99. 
cas tunecinas, que se han conservado y han llegado hasta nosotros. Pero la mayor parte de estos textos han sido perdidos ${ }^{3}$ o se encuentran aún en estado de manuscritos ${ }^{4}$. Son, sobre todo, los repertorios bio-bibliográficos los que nos han transmitido, a través de los siglos, informaciones sobre personajes sabios o devotos de aquel tiempo, algunos de ellos andalusíes o relacionados con esos inmigrantes moriscos.

Pero se echa de menos textos escritos sobre diversas manifestaciones culturales de esos moriscos o andalusíes, que sabemos existieron, pero que no han dejado testimonio escrito, $\mathrm{o}$ al menos no han llegado hasta nosotros o lo han hecho sólo fragmentariamente: cartas de los moriscos dirigidas a los sultanes otomanos $\mathrm{u}$ otras autoridades musulmanas ${ }^{5}$; cantos y poemas musicales, llamados en Tunisia "maluf" y cultivados por los andalusíes; cantos místicos que crecieron alrededor del mausoleo de Sidi Alí Azzuz, patrono del pueblo andalusí de Zaguán ${ }^{6}$; panegíricos al profeta o a santos del Islam, declamados por los adeptos de las cofradías en sus reuniones alrededor de las tumbas de esos santos situadas en los pueblos andalusíes ${ }^{7}$; inscripciones conmemorativas conservadas en muchos pueblos andalusíes ${ }^{8}$; estelas fune-

3. Francisco Ximénez cuenta, a principios del siglo XVIII (1727), que Muhámmad Guacir -probablemente el escritor andalusí Al-Wazir As-Sarradj, del que se hablará más adelantehabía escrito una historia del reino de Túnez y que le había sido traducida al español por el también andalusí Mahamet Andaluz. El mismo escritor español indica también que compró un libro de historia sobre la vida del profeta y de su familia. Ver M. DE EPALZA, «Nuevos documentos sobre descendientes de moriscos en Túnez en el siglo XVIII», Studia historica et philologica in honorem M. Batllori, Roma, 1984, pp. 195-228 (p. 214) y traducciones al francés y al árabe, en Revue d'histoire maghrébine, Túnez, 17-18, 1980, pp. 79-108, 137-140, y S.M. ZBISS; A GAFSI; M. BOUGHANMI y M. DE EPALZA, Études sur les morisques andalous, Túnez, 1983, pp. 57-90,67-70. No hay que confundir este escritor andalusí del XVIII con el conocido escritor morisco en castellano Muhámmad Alguacir, estudiado por G. WrEGERS, «Diplomatie et polémique anti-chrétienne: naissance et influence de l'oeuvre de Muhammad Alguacir (vers 1021-1612)», Actes du V symposium international d'études morisques sur "Le Ve centenaire de la chute de Grenade, 1492-1992", Zaghouan, 1993, pp. 747-756.

4. Ver fragmentos traducidos por A.M. TURKI, «Documents sur le dernier exode des andalous en Tunisie», en M. DE Epalza y R. PETIT, op. cit., pp. 747-756.

5. Ver A. TEMINI, «Une lettre des morisques de Grenade au sultan Suleiman al Kanuni en $1541 »$, Revue d'histoire maghrébine, Tunis, 3, 1975, pp. 100-105, y en id., Le gouvernement ottoman et le problème morisque, Zaghouan, 1989, pp. 23-32 (en francés) y 27-38 (en árabe).

6. Ver A. ABDESSELEM, Les historiens tunisiens des XVIIe, XVIIIe et XIXe siècles; essai d'histoire culturelle, París, 1973, p. 49. Sobre Zaghouan y los moriscos o andalusíes, ver texto del viajero español Francisco Ximénez en M. DE EPALZA, «Nuevos documentos...», p. 217, y síntesis histórica de A.H. GAFSI, "Zaghouan à l'époque islamique. Zaghouan et les Andalous», Zaghouan et sa région. Présentation historique, Zaghouan, 1990, pp. 5-7.

7. Ver, para la pequeña capital comarcal y rural andalusí de Testour, N.S. HopkiNs, «Notes sur l'histoire de Testour», en M.S. ZBiss et al., op. cit., pp. 103-128 (pp. 117-118).

8. Ver M.S. ZBISS, «La mosquée de Soliman», en M.S. ZBiss et al., op. cit., pp. 207-208, 39-44; A. DAOULATLI, «Inscription andalouse à la mosquée d'Al Alia», en M. DE EPALZA y R. PETIT, op. cit., pp. 282, 284, 285-290. Estamos preparando un corpus de las inscripciones en estos pueblos andalusíes de Tunisia. 
rarias de varios escritores del mismo origen ${ }^{9}$; cuentos populares cultivados en esos ambientes andalusies ${ }^{10}$. También merecen consideración literaria relatos de tradición oral ${ }^{11}$ y poesías cantadas en dialectal árabe (malhún) en muchos de esos pueblos ${ }^{12}$, manifestación de la expresión popular de esas comunidades andalusíes emigradas a Tunisia.

Podemos preguntarnos también por qué no se ha conservado ningún rastro de escritos, proyectos o tratados relacionados con algunas de las técnicas desarrolladas por los andalusies, como la artesanía de la chechía o "bonete tunecino"13 (como le llama Jovellanos), la construcción de importantes obras públicas andalusíes en arquitectura como el puerto militar de Ghar el Melh $^{14}$, el puente-presa de Batán ${ }^{15}$ o el minarete de la Gran Mezquita Zituna de Túnez ${ }^{16}$. Sólo se ha conservado un muy bello, único y muy interesante tratado de artillería escrito por Ibn Gánim ${ }^{17}$.

Otra cuestión que merece plantearse es el de la casi total ausencia de textos en lengua turco-osmanlí -co-oficial con el árabe en el Imperio Otomano, del que formaba parte la Regencia de Túnez en el siglo XVII- escritos por andalusíes, como los textos teológicos desarrollados por Ahmad Ax-Xarif Al-Andalusí1 18 .

9. He publicado una de ellas en Tunis, terre de rencontres et de civilisation, Túnez, 1992, p. 283.

10. Ver M.S. ZBISS, «Apports andalous en matière d'agriculture en Tunisie», en Actes du II symposium international du CIEM sur "Religion, identité et sources documentaires sur les morisques andalous", Túnez, 1984, p. 205.

11. Ver N.S. HOPKINS, op. cit., y M. DE EPALzA, Los moriscos antes y después de la expulsión, Madrid,

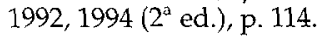

12. Es el caso de la colección de poemas de Al-Arbi An-Najjar, en el pueblo de Al-Alia (dactilografiado).

13. Ver S. Ferchou, Techniques et sociétés. Exemple de la fabrication des chéchia en Tunisie, París, 1971; P. TEYSSIER, «Le vocabulaire d'origine espagnole dans l'industrie tunisienne de la chéchia», en M. DE EPALZA y R. PETIT, op. cit., pp. 308-316, y más recientemente M. TuRKI, "Les Morisques en Tunisie: commercialisation de la chéchia dans la 2ème moitié du XIXe siècle», en A. TEMIMI (ed.), Actes du V symposium..., II, pp. 723-731.

14. Ver A. GAFSI, «La découverte d'une conduite d'eau dans un village morisco-andalous en Tunisie, Ghar el Melh (Porto Farina)», en Actes du V simposium..., pp. 283-290.

15. Ver A. GAFSI, «Crues, inondations et contrôle de l'eau dans quelques villages morisco-andalous en Tunisie», en Avenidas fluviales e inundaciones en la cuenca del Mediterráneo, Alicante, 1989, pp. 403-414.

16. Ver A. GAFSI, Monuments andalous de Tunisie, Túnez, 1993, pp. 24-25, id., «Aperçus sur les architectes Morisco-Andalous en Tunisie», Actes du IV symposium..., pp. 129-141. Ver descripción de un monumento emblemático de la instalación de los moriscos en la capital tunecina, aunque no trate de su decoración epigráfica, en A. ALMAGro GORBEA, «La záuiya de Sidi Qásim en Túnez», Tres monumentos islámicos restaurados por España en el mundo árabe, Madrid, 1981, pp. 93-131.

17. Ver infra, nota 42 .

18. Ver M. DE EPALZA, «Rites musulmans opposés aux rites chrétiens dans deux textes de morisques tunisiens: Ibrahim Taybili et Ahmed Al-Hanafi», en A. TEMIMI (ed.), Actas del III 


\section{POBREZA DE TEXTOS DE EXPRESIÓN ÁRABE Y ORIGINALIDAD DE LA LITERATURA EN LENGUA ESPAÑOLA}

El eclipse de las actividades culturales en la Regencia de Túnez, como resultado de las guerras, disturbios, hambrunas y epidemias que conoció el país por el conflicto hispano-otomano, particularmente alrededor de los años 1530$1574^{19}$, se manifiesta ante todo por el desinterés por las ciencias profanas, el abandono de todo esfuerzo intelectual personal en la ciencias religiosas (idjtihad) y por un auge triunfante de las prácticas espiritualistas de las cofradías y del marabutismo ${ }^{20}$ : poemas en elogio del profeta y de los santos, libros hagiográficos como los manákib del protector de los moriscos Abu-1-Gaith AlQaxxax ${ }^{21}$, poesía palaciega con temas elogiosos, sátiras, elegías y algunas invocaciones a santos del Islam. Son textos muy tradicionales, en esta época.

La enseñanza que se daba, en el siglo XVI y principios del XVII, tampoco permitía la evolución de esta literatura. La modernización de la docencia en Túnez no llegó prácticamente hasta la fundación de la Escuela Politécnica de El Bardo en 1838 y la introducción de una enseñanza moderna de tipo europeo.

Aunque la vida intelectual y literaria fuera favorecida y mantenida por el poder político, que lo utilizaba también como medio de propaganda, fundando, restaurando y manteniendo a las instituciones que dispensaban una cierta enseñanza (mezquitas, medersas o escuelas, záwiyas o capilla-oratorio de un personaje santo musulmán ${ }^{22}$, esta enseñanza dependía evidentemente de la religión musulmana y de su culto. Se trataba, en consecuencia, de una enseñanza tradicional, conservadora y conformista, vacía de toda reflexión constructiva, desprovista de comprensión y de explicación innovadora y que se limitaba a la lectura y paráfrasis de algunas obras religiosas. El método de enseñanza se basaba esencialmente en el dictado (imlá) hecho por el maestro.

symposium internacional de estudios moriscos Las prácticas musulmanas de los moriscos andaluces (1492-1609), Zaghouan, 1989, pp. 71-74, y id., "Arabismos en el manuscrito castellano del morisco tunecino Ahmad al-Hánafi», Homenaje a Álvaro Galmés de Fuentes, Madrid, 1985, II, pp. 517-527.

19. Ver A. MASMOUDI y M. SMIDA, «Tunis au XVIe siècle: de la chute des Hafsides à l'installation des Turcs», en Histoire de la Tunisie. Les temps modernes, Túnez, 1983, p. 15.

20. Ver J. FonTAINE, Histoire de la littérature tunisienne par les textes, vol. II: Du XIle siècle à l'indépendance, Túnez, 1994, p. 55; A. ABDESSELEM, op. cit., p. 24.

21. Ver A. AbDESSELEM, op. cit., p. 15, y M. DE EPAlZA y R. PETIT, op. cit., en capítulos diversos, especialmente de J.D. Latham (p. 42), H. Piéri (pp. 128-134, con fotografía de su tumba, en su mausoleo), M. de Epalza (pp. 156, 168), J. Oliver Asín (pp. 207, 208, 210), J. Penella (p. 258), S.M. Zbiss (pp. 275-276), J. Révault (p. 301), y F. Skhiri (p. 351).

22. Ver la institución y edificio más importantes de la actividad docente de los andalusíes de Túnez, en A. GAFsi, «La médersa des moriscos andalous à Tunis», Sharq al-Ándalus. Estudios Árabes, Alicante, 5, 1988, pp. 169-180. 
Sólo la mezquita Zituna, centro de estudios superiores de la teología malikí y de la ciencia religiosa islámica (ilm), se señalaba como institución que daba una enseñanza activa, rica y variada, gracias a los numerosos profesores célebres y a los diversos imames o predicadores de nivel intelectual eminente.

A pesar de la aportación étnica que supuso la llegada de los turco-otomanos, a partir de 1574, y de los moriscos, especialmente alrededor de 1600, la Regencia de Túnez no conoció el desarrollo de un mecenazgo cultural, con la notable excepción del Haznadar (equivalente a Ministro de Finanzas) del primer soberano de la dinastía husainí, Husáin Ibn-Alí (primer tercio del siglo XVIII). Era un personaje andalusí muy notable, que desempeñó un gran papel político e intelectual en la corte y que fundó una escuela y una biblioteca. Estos datos han sido proporcionados por el religioso trinitario español Francisco Ximénez, que residió en Túnez entre 1720 y 1735 y que mantuvo muchos contactos con él, por su cargo y también por su origen hispánico ${ }^{23}$.

La instalación de esas dos etnias nuevas en el país - los turcos y los moriscos-, con el uso más o menos limitado de sus lenguas respectivas, el turcoosmanlí y el español ${ }^{24}$, permitió el desarrollo de una literatura en lengua española rica y original, entre 1600 y $1639^{25}$. Las autoridades turcas tenían como lengua oficial del Imperio el turco-osmanlí de la administración otomana y los hispanos la lengua española usual en la sociedad española de la que provenían (el castellano, pero también el aragonés y el catalán-valenciano, a nivel oral) ${ }^{26}$, que todo condenaba a una desaparición paulatina, pero cuya existencia viva está atestiguada fehacientemente hasta mediados del siglo XVIII, tanto en algunas familias de la corte -los Lajua, recién venidos de Granada-, como en algunos pueblos de repoblación morisca del XVII, como Solimán y Testur (Tasatores, en textos en español).

Los moriscos expulsados de España, desaculturados por las visicitudes de las pruebas que habían sufrido en su patria y sin raices familiares y culturales en el país de acogida, han dejado una curiosa literatura en español ${ }^{27}$.

23. Ver los datos recogidos sobre este personaje y su familia, en M. DE EPALZA, «Nuevos documentos...», pp. 197-208.

24. Ver D. BRAHIMI, «Quelques jugements sur les maures andalous dans les régences turques au XVIII siècle», en M. DE EPALZA y R. PETIT, op. cit., p. 144. Sobre las relaciones entre los turcos otomanos y los andalusíes o moriscos, ver monografías de A. TEMIMI, Le gouvernement ottoman..., id., Études d'histoire morisque, Zaghouan, 1993, y M. DE EPALZA, «Les Ottomans et l'insertion au Maghreb des Andalous expulsés d'Espagne au XVIIe siècle», Revue d'Histoire Maghrébine, Túnez, 31-32, 1983, pp. 165-173.

25. Ver J. Penella, «Littérature morisque en espagnol à Tunis», en M. DE Epalza y R. Petrt, op. cit., pp. 187-198.

26. Ver M. DE EPALZA, «El català al Màgreb àrab. Els moriscos expulsats», Segon congrés internacional de la llengua catalana (1986), vol. VIII, Valencia, 1989, pp. 385-388.

27. Esta literatura hasta está relacionada con la mejor literatura española del Siglo de Oro, con Cervantes y Lope de Vega. Ver J. OlIVER Asín, «Un morisco de Túnez, admirador de Lope», 
Ésta había sido cultivada en la clandestinidad de España y escrita o copiada durante las primeras décadas de su implantación en Tunisia ${ }^{28}$.

A pesar de su ignorancia general del árabe y de la escritura que lo vehicula, los autores de estos textos han utilizado cierto léxico de esta lengua o de derivados del árabe, y han incitado a sus compatriotas a aprender el árabe. Esta lengua fue concebida como el cimiento que unía a los miembros de esta comunidad musulmana, un factor de cohesión y de solidaridad de los grupos, una manifestación de la identidad, un signo de reconocimiento y una marca de distinción $^{29}$. A las pruebas morales, religiosas y culturales sufridas en España, se añaden, pues, en el país de acogida, varios problemas de adaptación y de inserción en el seno de un nuevo entorno socio-cultural que les era extraño.

Los grandes temas de esta literatura morisca, en el exilio, siguen siendo profundamente religiosos y se articulan alrededor de los ejes siguientes:

- Comentarios de textos sobre las dos escuelas jurídico-teológicas sunníes dominantes en Tunisia, es decir los del malikismo tradicional en el Magreb y en Al-Ándalus y del hanifismo de los turcos-otomanos.

- Educación en castellano de los refugiados que ignoraban muchas de las creencias y de las prácticas fundamentales del Islam, como los ritos de las abluciones y de las oraciones. Este tema se evoca ampliamente por parte de los autores musulmanes de la Península, dirigiéndose a sus compatriotas bajo el dominio cristiano. Como ejemplo más notable y conocido, vease la obra de Ibn-as-Sabbah, escrita en Almería bajo la amenaza cristiana, alrededor del año $1489^{30}$.

Al-Andalus, Madrid, 1, 1933, pp. 409-456, id., «El Quijote de 1604», Boletín de la Real Academia Española, Madrid, XXVIII, 1948, pp. 89-126 [Trabajos traducidos al francés, en M. DE EPALZA y R. PETIT, op. cit., pp. 205-239 y 240-247, respectivamente] y el estudio de Luce LópezBaralt, mencionado supra, nota 2. Ver también el análisis de un soneto, de perfecta estructura clásica, en A. GALMÉS DE FUENTES, «Sobre un soneto barroco de un morisco», Archivum, Oviedo, XXVII-XXVIII, 1977-1978, pp. 200-217.

28. Ver M.N. BEN JEMIA, "Le bilinguisme morisque à travers la littérature aljamiada», en Actes du II Symposium..., I, p. 43, id., La langue des derniers musulmans de l'Espagne, Túnez, 1987. Análisis interesante de L.F. Bernabé PONS y J.J. MARTínez EGIDO, «Estado de la lengua de los manuscritos en caracteres latinos. El problema religioso», Actes du IV symposium..., pp. 3541. Maduras reflexiones de O. HEYGI, «Implicaciones lingüísticas del contexto religioso-cultural de la literatura aljamiada», A. TEMIMI (ed.), Actes du II symposium..., I, pp. 375-379.

29. Ver la articulación de este factor lingüístico de identidad de los inmigrantes, en L. CARDAILLAC, «Le Turc, suprême espoir des morisques», en S.M. ZBISS et al., op. cit., p. 53, y M. DE EPALZA, «Le lexique religieux des morisques et la littérature aljamiado-morisque», en L. CaRdaIllac (ed.), Les Morisques et l'Inquisition, París, 1990, pp. 51-64. Nuevas reflexiones de M. SÁNCHEZ ÁlVAREZ, "Actitudes lingüísticas de los moriscos, deducidas de fuentes cristianas y aljamiadas», en A. Temimi (ed.), Actes du V symposium ..., II, pp. 633-641, y de A. y L.M. SERRY, «La identidad árabo-islámica de los moriscos a través de la literatura aljamiada», ibídem, pp. 695-709 [texto árabe, en vol. I, pp. 151-168].

30. Ver D. CHeIKHA, «Quelques aspects religieux du récit de voyage de Abdallah Ibn al Sabbah», en A. TEMimi (ed.), Actes du IV symposium..., p. 356. Ver presentación del personaje 
- Comentarios pseudo-proféticos sobre el Islam, sobre el destino de España y sobre los horrores del Día Final.

- Relatos bio-hagiográficos relacionados con el Profeta, con los imames y con los demás personajes santos del Islam.

- Profecías relacionadas con el Turco como salvador, castigador de los cristianos y "esperanza suprema de los moriscos" 31 .

- Polémicas religiosas contra los cristianos y los judíos.

Se trata, pues, de unos textos marcados por el fervor religioso que ha podido resistir a las pruebas de la Inquisición y del exilio, que muestran la fidelidad de los refugiados hispanos al Islam, a sus dogmas y a la cultura islámica $^{32}$.

Al lado de estos temas, las evocaciones del exilio y de la caída de España [la musulmana, evidentemente] ocupan un lugar destacado y fueron escritos con un arte que recuerda la literatura hispana contemporánea ${ }^{33}$.

El sentimiento de dolor y de nostalgia por la tierra perdida, su grandeza, sus méritos, sus valores y su prestigio, el exilio y el desarraigo, fueron concebidos y percibidos como un castigo divino y una fatalidad.

Este mundo espiritual está dominado, al mismo tiempo, por la ansiedad religiosa y el desarraigo étnico y cultural, favoreciendo y nutriendo el misticismo, forma suprema de éxtasis religioso ${ }^{34}$.

Esta literatura, que emana de las meditaciones profundas sobre la condición del hombre, introduce en el pensamiento islámico tradicional nuevas formas de cultura, nacidas en la España del Renacimiento y sin relación directa con la herencia y el legado de la civilización de la España musulmana o Al-Ándalus, como lo fuera la cultura transmitida a Tunisia por la comunidad andalusí refugiada en la Ifrikiya hafsí anterior al período otomano del país $(1230-1569)^{35}$.

y de su obra en artículo de F. Franco Sánchez, en este mismo volumen de la revista Sharg Al-Ándalus. Estudios mudéjares y moriscos.

31. Ver L. Cardaillac, op. cit.

32. Ver M. DE EPALZA, «L'identité onomastique et linguistique des morisques», en A. TemimI (ed.), Actes du II symposium..., pp. 269-279.

33. Ver trabajos de J. Oliver Asín mencionados supra, nota 27.

34. Ver J. Penella, op. cit., p. 196.

35. Ver M. TALBI, «Les contacts culturels entre l'Ifriqiya hafside (1230-1569) et le sultanat nasride d'Espagne (1232-1492)", en Actas del II coloquio hispano-tunecino, Madrid, 1973, pp. 63-90; M.J. RUBIERA MATA, «Un aspecto de las relaciones entre la Ifriqiya hafsí y la Granada Nasrí: la presencia tunecina en las tarîqât místicas granadinas», Les Cahiers de Tunisie. Actes de la 3ème Rencontre Tuniso-Espagnole, Túnez, XXVI/103-104, 1978, pp. 165-172. 


\section{FUENTES, SABIOS Y LITERATOS DE LA LITERATURA EN ÁRABE}

Las crónicas tunecinas, que son las fuentes documentales principales de que disponemos, se interesan sólo marginalmente por la actividad literaria de los descendientes de los inmigrantes españoles, asignando un papel más o menos importante a las biografías de personajes religiosos y literarios ${ }^{36}$.

Se encuentra a menudo entre ellos a sabios en teología y a letrados distinguidos, que tienen la nisba ("nombre de origen") de Al-Andalusí ("oriundo de Al-Ândalus", es decir de la Península Ibérica musulmana). Este nombre de origen o apellido familiar étnico de Al-Andalusí, con el que se designa a esos sabios o literatos, es un medio eficaz de conservar la identidad como musulmán originario de Al-Ándalus (aunque no siempre permita fechar su emigración al Magreb: ¿en la gran expulsión final de 1609-1614? ¿en períodos anteriores de la historia ibero-magrebí?).

Estos escritores han dejado cierto impacto en la vida literaria del país, entre los años 1603 y 1838, y aún más tarde ${ }^{37}$, en la sociedad de inserción, gracias a su integración rápida y total en la cultura árabe e islámica.

En estas biografías, confeccionadas de forma muy idealista y hagiográfica, la importancia fundamental reside en la moralidad y las altas cualidades morales y de erudición del personaje. Para captar mejor este aspecto, hemos escogido y acumulado, en una biografía ficticia, algunos ejemplos de epítetos que se suelen multiplicar en estas biografías y que ilustran con casos concretos el género biográfico habitual de la época.

"Conocido por su alta moralidad, su integridad, su probidad, su dignidad, su serenidad, su virtud y su delicadeza, animado de un espíritu de benevolencia y de piedad, famoso por su devoción, su ascetismo, tratado con honor, escuchado y alabado, el letrado o el sabio $X$, por su comportamiento ejemplar, llega a hacerse respetar y a ser venerado por el pueblo".

La ciencia o erudición se manifiesta por su conocimiento de muchas ciencias, disciplinas y ramas del saber.

"El sabio $X$ es experto en el conocimiento de muchas ciencias religiosas fundamentales, como la teología (ilm al-kalam o figh), la lógica (mántiq), la mística (tasáwwuff), la exégesis coránica (tafsir), la retórica (balaga), la recitación melódica del Corán (tadjwid), las particiones de herencias (faraid), apasionado por las ciencias de la lengua, como la sintaxis (nahw), la morfología gramatical (sarf), entusiasta de la literatura, tanto por la poesía (xir) como por la historia y las biografías (ajbar), era respetado por su inteligencia y su elocuencia.

36. Ver A. ABDessalem, op. cit.

37. Ver A. GAFSI, «Ar-rihla al-andalusiyya», Awrâq, Madrid, 5-6, 1982, pp. 115-130, y P. MARTínEZ MONTÁVEZ, «Un poeta morisco contemporáneo: Abd al-Razzâq Karabâka (19011945)", Actas del II coloquio hispano-tunecino de estudios históricos, Madrid, 1973, pp. 235-259. 
Su cultura resultaba tan sólida que pudo participar en justas literarias y poéticas, frecuentar los "círculos» del saber y animarlas gracias a su ciencia y a su genio. Encarna también la cultura y los gustos de su tiempo y contribuye, consecuentemente, a la difusión de la cultura de su país.

Se entregó paralelamente a la enseñanza. A sus cursos se apresuraba una muchedumbre de estudiantes y de escritores. Contribuyó también a la formación de numerosos discípulos y fue el gran maestro de muchos sabios y escritores de su tiempo. Frecuentó también la élite intelectual del país y se encontró con eminentes especialistas y hombres del saber, con ocasión de la peregrinación a La Meca. Algunos de ellos le concedieron la idjaza, especie de licenciatura honoris causa, que le autorizaba a transmitir y a difundir las obras o la enseñanza del maestro".

La producción intelectual figura también en un lugar importante en estas biografías, donde se describe cómo habían compuesto "diversos tratados o epístolas (risala) sobre diversas disciplinas en un estilo florido, o con una prosa rimada y un lenguaje asonante (sadja). Su obra escrita tuvo una gran audiencia ante los letrados".

Todas estas cualidades le disponían para ser predicador (jatib) en la Gran Mezquita Zituna, un gran clérigo (faqih) o a ser nombrado muftí, encargado de responder a las consultaciones jurídicas oficiales.

\section{ALGUNOS EJEMPLOS DE ESTA LITERATURA}

Como ejemplos de esos textos referidos a andalusíes, mencionaremos solamente a tres escritores en árabe, del siglo XVII y principios del XVIII.

A. El libro Al-anwar an-nabawiyya fi abá jair al barriyya, cuyo título puede traducirse como "Las luces proféticas acerca de los antepasados de la más excelente de las criaturas (Muhámmad)", es una obra escrita en árabe en $1044 \mathrm{H} / 1634$ por Muhámmad Ibn-Abd-Ar-Rafí Ibn-Muhámmad Ax-Xarif ${ }^{38}$ Al-Husaini Al-Djáfari Al-Mursi ${ }^{39}$ Al-Andalusí, muerto en 1642. El texto fue compuesto a petición de su amigo Ax-Xarif An-Nawali, apodado As-Sarradj ("El Guarnicionero") 40 .

Esta obra autobiográfica, consagrada a la genealogía del Profeta, de sus compañeros y de sus descendientes, está destinada a convencer a los tunecinos de que entre los refugiados venidos de España había también nobles jerifes o cherifes (xarif, plural xurafá o chorfas) descendientes del Profeta o de sus Compañeros (sahaba), para que les admitieran como tales en esa nobleza

38. "El Noble", por ser descendiente del Profeta Mahoma.

39. "El Murciano", de origen murciano más o menos lejano.

40. Fragmentos traducidos al francés en A. TURKI, op. cit. 
de religión, que tenía su asociación en Tunisia. Se trata pues de una obra de tema religioso, pero también de reivindicación nobiliaria andalusí.

El análisis rápido de esta obra muestra que se compone de varias partes. Comienza por la enumeración de los ascendentes del Profeta Muhámmad (Mahoma) y de sus Compañeros, a la que sigue su apología. Presenta a continuación un resumen de la historia de Al-Ándalus. Esta apología está destinada a mostrar que hay musulmanes de España que son descendientes del Profeta del Islam.

La obra comprende también una larga exposición sobre la lucha y la resistencia heroica "de los últimos musulmanes de España, contra la Inquisición, la persecución, la tortura y la prohibición de las prácticas religiosas islámicas". Explica cómo su padre le enseñó el alfabeto árabe y el Corán, cómo se vio obligado a frecuentar la escuela cristiana y cómo se encontró con varios musulmanes virtuosos en Jaén, Granada, Córdoba, Sevilla, Toledo, etc., para fortalecer y conocer mejor la fe de sus antepasados, lo cual constituye un capítulo importante de esta obra.

El fracaso de la política inquisitorial llevada por los reyes de España, la adhesión a las prácticas religiosas islámicas practicada secretamente por los moriscos y el temor de que se concretara la alianza entre éstos y el poder otomano son evocados como las razones esenciales que habían provocado su expulsión de España y sus consecuentes desgracias.

El exilio de más de 600.000 personas, su implantación en Argel, Annaba (Bona), Tetuán, Fez, Marrakech, Belgrado, Bursa y Constantinopla (Estambul), la instalación de sus antepasados en Túnez (en el Zukak AlÁndalus o "calle de los andalusíes") en 902/1496, y, finalmente, la acogida favorable reservada a los recién llegados por el dey o "virrey" tunecino, delegado del poder otomano, Uthmán Day (1598-1610) y por el santo Abu-1Gaith Al-Qaxxax se describen con mucha emoción, amargura y calor.

En esta importante obra se trasluce, pues, la expresión del sufrimiento y del dolor. Esta literatura en árabe de los andalusíes tunecinos, que quedó profundamente marcada por la tragedia, muestra, al mismo tiempo, una triple alienación, religiosa, cultural y social.

Haciéndose eco de las quejas de sus compatriotas musulmanes venidos de España, presentándose como el portador de su memoria colectiva y el representante de una comunidad étnica víctima de una política "belicosa", este autor ha producido una obra "comprometida" y "militante", que manifiesta claramente una búsqueda de identidad y una voluntad de especificidad étnica.

$\mathrm{Al}$ atribuirse y reivindicar una genealogía gloriosa, de noble descendiente del Profeta y de andalusí, al utilizar una argumentación musulmana muy tradicionalmente documentada pero con "acentos de hidalgo español" y en un ambiente de "pureza de sangre" típica de la literatura del Siglo de 
Oro español y cristiano ${ }^{41}$, el autor busca, a pesar del carácter idealista de este texto, asegurarse las condiciones para una mejor integración de su comunidad en el grupo social de acogida.

B. El libro Kitab al-izz wa-l-manafi li-l-muchahidín fi sabil Allah bi-l-madafi ("Libro del honor y de las cosas útiles, para los que hacen la guerra santa según la voluntad de Dios, con las armas de fuego" ").

Se trata del primer tratado completo de artillería escrito en árabe, según su autor Ibrahim Ibn-Áhmad Ibn-Gánim Al-Andalusí, conocido con el apodo de Al-Marmax o Arribax (quizás transcripción del nombre hispano El Barbas o Arribas $)^{42}$. Este hermosísimo libro, lleno de dibujos, fue traducido del español por Áhmad Ibn-Qásim Al-Hádjari, llamado Bejarano, otro morisco que jugó un papel importante entre los moriscos exiliados, como intérprete en la corte del sultán marroquí Al-Mansur Adh-Dháhabi (1578-1603) y de sus sucesores $^{43}$. La traducción se acabó en Túnez, el 10 del mes rabí-II de 1048, 21 de agosto de 1638 .

Este libro es uno de los raros testimonios sobre el paso de los moriscos españoles al Nuevo Mundo, como lo indica esta citación sacada del libro: "Me gustaba mucho viajar por los océanos. Emprendí varias veces la travesía [a América] y viajé en un gran navío llamado en español [en aljamía o "lengua extranjera al árabe"] "galeón", que traía cantidades ingentes de dinero de las lejanas Indias Occidentales..."44.

Esta obra "literaria" y "técnica" empieza por una biografía del autor, pero es sobre todo un manual práctico sobre la importancia de la artillería en la estrategia militar de la época y una obra de arte de excepcional belleza, por los croquis y esquemas que figuran en el libro ${ }^{45}$.

41. Ver M. de Epalza y R. Petit, op. cit., p. 114. Ver, aún en la Península Ibérica, M. OjedARENTAS, «Literatura de ficción: arma política de resistencia para los moriscos españoles del siglo XVI», en A. TEMIMI (ed.), Actas del III Simposio Internacional de Estudios Moriscos. Las Prácticas Musulmanas de los Moriscos Andaluces, Zaghouan, 1989, pp. 151-160.

42. Ver A. TURKI, op. cit., y A. GAFSI, «L'historiographie musulmane et le problème morisque», en L. Cardaillac (ed.), Les Morisques et l'Inquisition..., p. 199.

43. Sobre este importante personaje andalusí del exilio, ver su autobiografía en árabe, el libro Násir ad-din ala qaum al-kafirin, editado y estudiado por M. Razuq, Casablanca, 1987, y con traducciones parciales al italiano y/o al francés [siete trabajos en la bibliografía de L.F. BERNABÉ PONS, op. cit., pp. 113-114, algunos de ellos traducidos al francés en M. DE EPALZA y R. PETrT, op. cit.]. Ver estudios de L.P. HARVEY, "The morisco who was Mulay Zaidan's spanish interpreter», Miscelánea de Estudios Árabes y Hebraicos, Granada, VIII/1, 1959, pp. 67-97, id., «Textes de littérature religieuse des moriscos tunisiens», en M. DE EPALZA y R. PETIT, op. cit., p. 199.

44. Ver A. GAFSI, «Ibn Ganim, le "tunisien" entre l'Espagne et le Nouveau Monde et l'introduction de la fabrication des canons à Tunis", en Hommes et Monuments, Túnez, en prensa.

45. Ver D. JAMES, «The Manual de Artilleria of al-racis Ibrahim h. Ahmad al-Andalusi with particular reference to its illustrations and their sources», Bulletin of the School of Oriental and African Studies, Londres, XLI, 1978, pp. 237-271. 
El libro comprende una introducción y cincuenta capítulos, que se articulan alrededor de los siguientes temas:

- papel de la artillería en las guerras.

- los diferentes tipos de cañones utilizados en España en el siglo XVII.

- las partes de los cañones: ruedas, fuste, mirilla, sistema de encendido, etc.

- los consejos prácticos para un buen empleo de los cañones.

- las técnicas de asalto.

- la estrategia militar, de la organización militar y de las técnicas de desarrollo del armamento.

- las ofensivas navales realizadas por los musulmanes en el litoral de España y de Italia, que son una forma de djihad o "guerra santa" y una forma de apoyo a la Sublime Puerta turco-otomana.

Estos diversos temas están inspirados, evidentemente, por su vida y su actividad en la flota imperial española, como técnico y artillero en sus diferentes viajes, entre otros al Nuevo Mundo.

Ibn Gánim estaba encarcelado en Sevilla, por un asesinato, cuando se promulgó el decreto de expulsión de los moriscos. Reclamó y consiguió ser expulsado, poniéndose inmediatamente al servicio de las armadas musulmanas.

Por su competencia, su espíritu de iniciativa y sus conocimientos prácticos, fue encargado por el gobernador tunecino Uthmán Dey de formar artilleros en La Goleta, uno de los más importantes puertos de la Regencia de Túnez en esa época.

Practicó el corso en el Mediterráneo y fue capturado cerca de Málaga, en el mes de agosto de 1610. Estuvo encarcelado en la cárcel de Sevilla, hasta que la influencia de amigos le permitió liberarse, en 1617.

Fue nombrado por Yusuf Dey comandante de la marina tunecina en el puerto de La Goleta, donde promovió la instalación de una "industria de armamentos" de montaje de cañones y de una organización militar eficaz.

C. El libro Kitab al-hulal as-sundusiyya fi l-ajbar at-tunisiyya ("Libro de las togas de seda, sobre informaciones de Tunisia") ${ }^{46}$.

Esta importante obra histórica y literaria fue escrita por Abu-Abd-Allah Muhámmad Al-Andalusí, conocido bajo el nombre de Al-Wazir As-Sarrach ("El Ministro -o quizás El Alguacil-El Guarnicionero"), muerto en 1737 y

46. Esta obra ha sido editada, en varios volúmenes, por M.H. El Hila, Beirut, 1984-1985. Este mismo erudito tunecino la presentó en «L'élément andalou en Tunisie, selon le "Hulal AlSundusiyya" d'Al-Sarradj Al-Andalusi», en M. DE EPALZA y R. PETT, op. cit., pp. 264-266. 
descendiente de una familia española emigrada a Tunisia probablemente en el siglo XVII.

Se trata de una crónica que describe la historia de Tunisia, desde la conquista árabe de 647 hasta el reinado de Husáin Ibn-Alí (1705-1740), fundador de la dinastía husainí que gobernó el país hasta 1958, fecha de la proclamación de la República.

Esta obra monumental es también una compilación y una mezcla de historia, de literatura y de hagiografía. Su autor utiliza mucho a autores árabes de la Edad Media (Abu-l-Fidá, As-Sáfadi, Ibn-Hallikán, At-Tidjani...), así como a cronistas tunecinos anteriores (Ibn-Abi-Dinar, Husáin Hudja, Áhmad Burnaz...) y fuentes orales.

Esta historia está entremezclada con leyendas, anécdotas y panegíricos de los santos, como el que consagró a Sidi Alí Azzuz, patrón de la ciudad andalusí de Zaguán. Comparte "la deferencia y la veneración de sus compatriotas y contemporáneos por estos piadosos personajes" ${ }^{\prime \prime}$.

Junto a estas preciosas informaciones históricas, Al-Wazir As-Sarrach evoca con mucha finura y encanto las biografías de los imames de la Gran Mezquita Zituna, donde él enseñó también, así como las de los personajes que le habían educado y de los sabios que había conocido.

En esta obra, el autor hace el elogio de los Otomanos, que habían gobernado a Tunisia desde 1574, y sobre todo del fundador de la dinastía husainí, Husáin Ibn-Alí, por su obra arquitectónica e intelectual, pero no consagra más que un párrafo a la llegada de los moriscos a Tunisia y a la obra que hicieron. Tampoco se distingue por juicios favorables a los andalusíes y por una hostilidad particular hacia los españoles. La expulsión y su impacto en la sociedad tunecina ya están lejos...

El autor se interesa también por describir monumentos erigidos por los otomanos y más particularmente por los santuarios, sus leyendas y sus costumbres, sean en Túnez o en otras regiones del país.

Al lado de esta obra "literaria", Al-Wazir As-Sarrach ha escrito poemas panegíricos celebrando y conmemorando la obra arquitectónica de Husáin Ibn-Alí y su generosidad para con los sabios y escritores del país, así como trenos y misivas dirigidas a sus pares o condiscípulos. Estos mismos temas políticos se encuentran también desperdigados en su crónica.

47. Ver A. AbDESSELEM, op. cit., p. 232. 


\section{CONCLUSIÓN}

La originalidad y la riqueza de la literatura tunecina en lengua española producida por los moriscos exiliados en Tunisia durante las primeras décadas del siglo XVII son ya muy conocidas.

Los temas de esta literatura tienen cierta relación con los de la literatura en lengua árabe, producida durante este mismo período por los moriscos o andalusíes "arabizados". Tocan los campos de la polémica anticristiana, los relatos biográficos relacionados con el Profeta o históricos que tratan de historia de Al-Ándalus. Sólo la obra de Ibn-Gánim sobre la utilización de los cañones se sale de esta clasificación.

La literatura morisco-andalusí tardía no es abundante y se relaciona con los grandes tema de la literatura árabe clásica. Al-Wazir As-Sarrach queda como uno de sus representantes más eminentes. Pero ningún trabajo de conjunto ha sido realizado aún sobre la literatura de expresión árabe escrita por esos moriscos y por sus descendientes.

[traducción al español de Míkel de Epalza] 


\section{Savants et lettrés moriscos andalous aux XVIIè, XVIIIè et XIXè siècles}

\begin{tabular}{|c|c|c|c|c|}
\hline Noms & né en & $\begin{array}{c}\text { était mort } \\
\text { en }\end{array}$ & mort en & carrière \\
\hline 'Abd al Kadir Ibn Asur al Andalussï & & & 1756 & $\begin{array}{l}\text { Cheikh de la zaouia de Sidi cAli Zwāwi. Connu pour son } \\
\text { mysticisme (1). }\end{array}$ \\
\hline Abù ar Rabic al Andalussi & & 1702 & & Professeur à la mosquée Zitouna (2). \\
\hline Ahmad as Sarif al Andalussi & & & 1650 & $\begin{array}{l}\text { Ancien étudiant à Sarajevo ét à Bursa. Anteur de plusieurs } \\
\text { livres religieux, Predicateur à la mosquée Youssef Dey. } \\
\text { Mufti hanéfite (3). }\end{array}$ \\
\hline 'Ali al Andalussi & & 1708 & & $\begin{array}{l}\text { Professeur de théologie à la mosquée Zitouna et jurisconsu- } \\
\text { late (fakih) (4). }\end{array}$ \\
\hline ¿Ali al Azhari al Andalussĩ & 1648 & & & Professeur à al Azahar au Caire et à Sousse en Tunisie (5). \\
\hline 'Ali al Hadrawi al Andalussi & & & 1655 & Leftré connu pour sa piété et son mysticisme (6). \\
\hline Hamada ar Riklij al Andalussi & & & 1748 & Prédicateur à la mosquée Zitouna, cadi et jusrisconsulte (7). \\
\hline Hmida al Hirmìiū al Andalussi & & 1670 & & Professeur de Hadi (tadition prophétique) (8). \\
\hline Ibrahim as Şarakustị al Andalussĩ & & 1679 & & Savant et auteur de pluseiurs livres (9). \\
\hline Manșür an Nàsar al Andalussī & & & 1678 & $\begin{array}{l}\text { Un des grands mystiques, de son temps, il fut comparé à } \\
\text { Ibn Arabi (10). }\end{array}$ \\
\hline Muhammad al Andalussi & & & 1608 & Prédicateur à la mosquée Zitouna (11). \\
\hline Muhammad al Hageggal Andalussì & & & & $\begin{array}{l}\text { Professeur à la mosquée Zitouna et maitre d'as Sarraget aut- } \\
\text { teur de sept ouvrages (12). }\end{array}$ \\
\hline Muhammad ai Masat al Andalussï & & & 1834 & $\begin{array}{l}\text { Professeur à la mosquée Zitouna, spécialiste de l'exegèse } \\
\text { coranique et la théologie (13). }\end{array}$ \\
\hline Muhammad Ibn 'Asür al Andalussi & & & 1698 & $\begin{array}{l}\text { Comnu pour son mysticisme, cheikh de la zaouia de Sidi Alt } \\
\text { Zwawi (14). }\end{array}$ \\
\hline $\begin{array}{l}\text { Muhammad lbn Hamda ar Rikli } \\
\text { al Andalussi }\end{array}$ & & 1726 & & $\begin{array}{l}\text { Professeur à la mosquée Zitouna et à la medersa al muradi- } \\
\text { ya à Tunis (15). }\end{array}$ \\
\hline Muhammad Ibn Mustafāal Andalusst & & 1740 & & $\begin{array}{l}\text { Gran maître mystique, prolesseur à la medersa du cais } \\
\text { Murad(16). }\end{array}$ \\
\hline Muhammad Madūr al Andalussi & & & 1811 & $\begin{array}{l}\text { Professeur à la mosquée Zitouna et à Soliman, cadi et poète } \\
\text { (17). }\end{array}$ \\
\hline Muhammad Nuina al Andalussi & & & 1679 & Professeur de Hadith (18). \\
\hline Saban al Andalussi & & 1625 & & $\begin{array}{l}\text { Jer professeur de la medersa des Andalous fondée en } 1625 \\
\text { (19). }\end{array}$ \\
\hline Sulaymān al Andalussĩ & & 1707 & & $\begin{array}{l}\text { Protesseur de grammaire et cheikh de la medersa des } \\
\text { Andalous a Tunis }(20) \text {. }\end{array}$ \\
\hline \multicolumn{4}{|c|}{$\begin{array}{l}\text { 1.Ben Achour, l'tineraire d'une famille tunisienne.. in M. de Epalza y R. Petit, } \\
\text { op. cit., p. } 21 \text {. } \\
\text { 2. Sarrag, } 11,678 \text {. } \\
\text { 3. Huga, Dayl, Tunis, } 1975, \text { pp. } 170,344,655 \text {. } \\
\text { 4. Sarrag, II, } 493,655 \text {. } \\
\text { 5. A. Abdesselem, } 44 \text {. } \\
\text { 6. Sarrag, II, } 416 \text {. } \\
\text { 7. A. Abdesselem, } 198 \text {. Huga, } 66 . \\
\text { 8. Huga, } 123,268 \text {. } \\
\text { 9. Huga, } 187 . \\
\text { 10. Huga. } 275 \text {. }\end{array}$} & $\begin{array}{l}\text { 11. Huga, 64. } \\
\text { 12. Abdesselem, 176. Huga 199. Sarrag II. } \\
\text { 13. Ibn abi Diaf, VII (1966) 19. } \\
\text { 14. Ben Achour, op, cit, p. } 15 . \\
\text { 15. Huga, 261. J. Fontaine, } 78 . \\
\text { 16. Huga, 268. Sarrag, III, } 354 . \\
\text { 17. J. Fontaine, 82. } \\
\text { 18. Sarrag, II, 488. } \\
\text { 19. Sarrag, 265. Huga, 297. } \\
\text { 20. Sarrag, III, 492, 656, A. Gafsi, la medersa, of. cit. }\end{array}$ \\
\hline
\end{tabular}




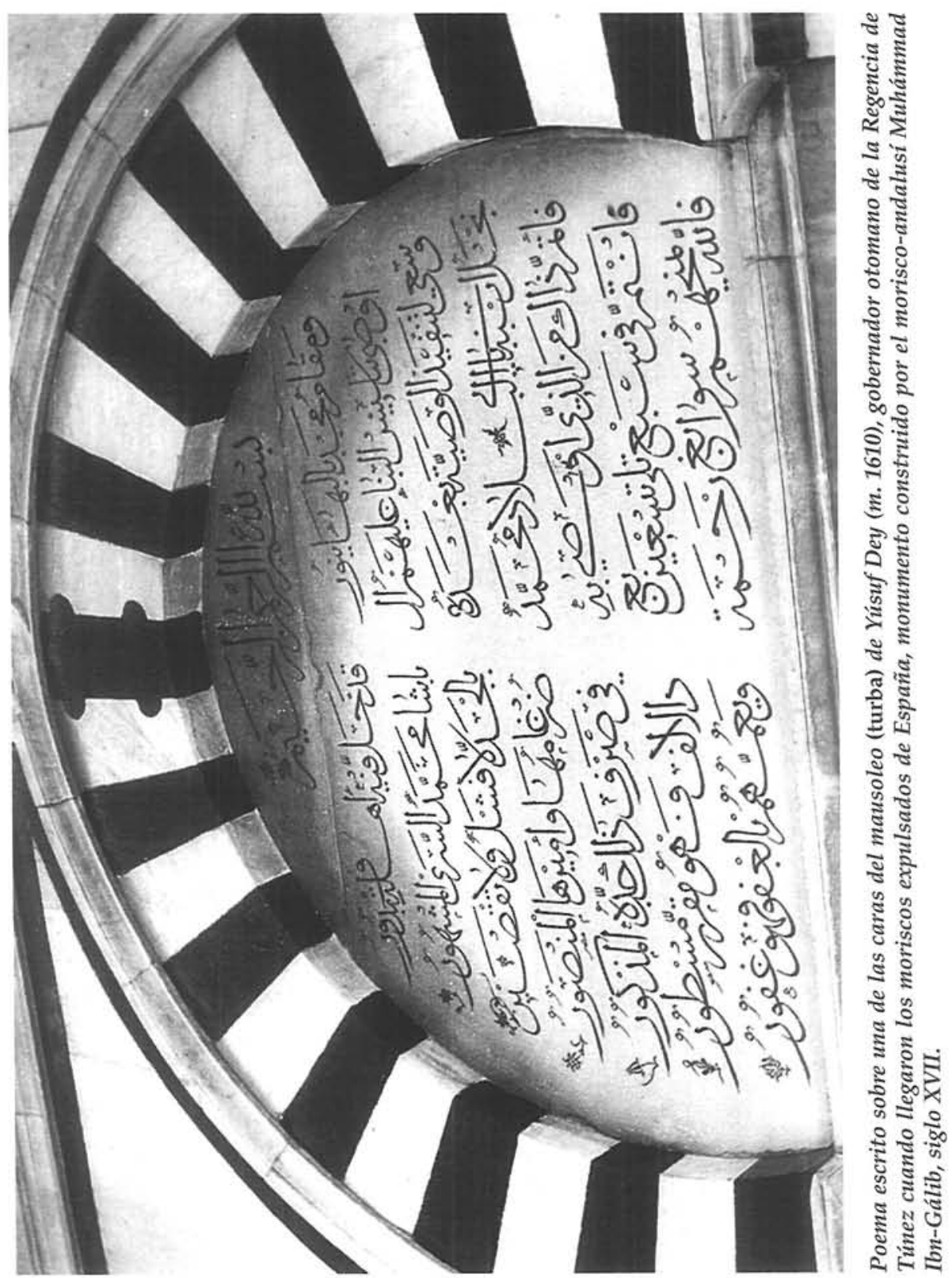

